Its average size is $6 \times 3 \mathrm{~cm}$ and it may be shown in all adults; it communicates with the hip in $14 \%$ of cases. ${ }^{1}$ Iliopsoas bursitis may occur at any age and is most often the result of acute or recurrent trauma; it may also occur in any condition which produces a generalised bursitis or synovitis. ${ }^{2}$ It usually presents as a mass in the groin with pain referred to the knee, and tenderness can almost always be elicited immediately below the midpoint of the inguinal ligament. ${ }^{3}$ The pain which is usually referred to the knee and aggravated by extension of the hip, is probably the result of entrapment of the femoral nerve in the femoral canal. ${ }^{2}$ Differential diagnosis usually includes inguinal lymphadenopathy, femoral hernia, aneurysm of the femoral artery, and psoas abscess. Retro-peritoneal extension may occur with displacement of the bowel or ureter and, more rarely, pressure on the femoral vein may produce oedema of the leg. ${ }^{45}$

Iliopsoas bursitis is not a commonly recognised cause of pain in the hip, referred pain in the knee, or a mass in the groin, still less as a cause of a swollen leg. This collection of symptoms and signs should alert the clinician to the possibility of iliopsoas bursitis, even in the absence of hip arthritis. A careful history and clinical examination will help to confirm or exclude the diagnosis, and ultrasonography should resolve any further difficulties and obviate the need for surgical exploration.

${ }^{1}$ Chandler SB. The iliopsoas bursa in man. Anat Rec 1934;58:235-40.

2 Bywaters EGL. Lesions of bursae, tendons and tendon sheaths. Clinics in Rheumatic Diseases 1975;5:883-926.

${ }^{3}$ O'Connor DS. Early recognition of iliopectineal bursitis. Surg Gynecol Obstet 1933;57:674-84.

4 Melamed A, Bauer CA, Johnson JH. Iliopsoas bursal extension in arthritic disease of the hip. Radiology 1967;89:54-8.

${ }^{5}$ Armstrong P, Saxton H. Iliopsoas bursa. Brf Radiol 1972;45:493-5.

(Accepted 18 December 1980)

Rheumatic Diseases Unit, University of Edinburgh, Northern General Hospital, Edinburgh EH5 2DQ

M J FORD, MRCP, senior registrar

A G MARTYNOGA, MRCP, senior registrar

G NUKI, FRCPED, professor of rheumatology

\section{Scleroderma in the elderly}

Scleroderma in the elderly is generally held to be a benign condition in which systemic disease is rare. We report on two patients, however, one of whom had widespread systemic disease and a rapidly fatal course.

\section{Case report}

CASE 1

An 80-year-old man was referred with severe proximal myopathy, Raynaud's phenomenon of recent onset, and weight loss of $19 \mathrm{~kg}$ over the preceding two years. There was acrosclerosis of the hands with small areas of necrosis on the finger tips, facial scleroderma and telangiectasias, and

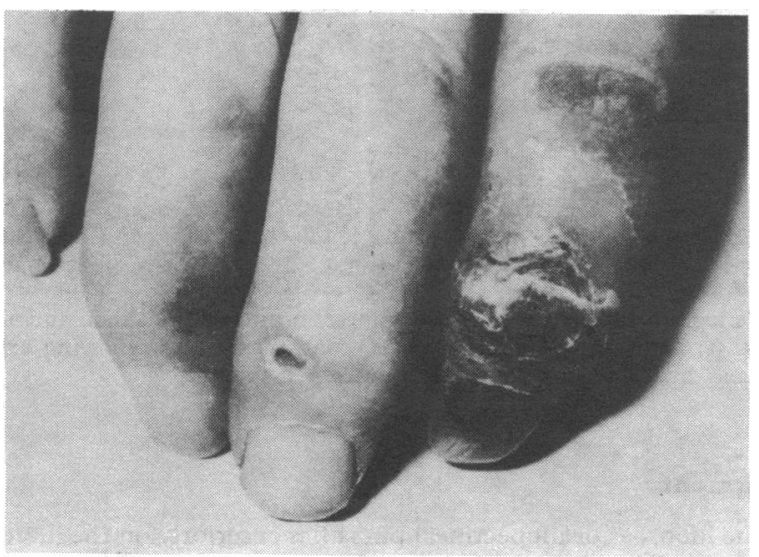

Gangrene of finger tip (case 1) synovitis of the interphalangeal joints and wrists. Proximal muscles were weak and wasted. Haemoglobin concentration was $11.2 \mathrm{~g} / \mathrm{dl}$, erythrocyte sedimentation rate $52 \mathrm{~mm}$ in 1 st hour, and the antinuclear factor test positive at 1 in 160. Creatine phosphokinase activity was raised at $940 \mathrm{IU} / \mathrm{l}$, but a needle biopsy specimen of the quadriceps showed only type II fibre atrophy. A latex test was negative and thyroid function tests normal. Radiology showed moderate cardiac enlargement with interstitial changes in the mid and lower lung zones. Lung function tests showed a restrictive defect with distinct reduction of transfer factor $\left(T_{L}\right.$ CO $5.6 \mathrm{ml} / \mathrm{min} / \mathrm{mm} \mathrm{Hg}$ (predicted 24.5)).

Progressive systemic sclerosis with active myositis and fibrosing alveolitis was diagnosed and treated with prednisolone $40 \mathrm{mg}$ daily. Eight months later he developed gangrene of the tips of several fingers, necessitating amputation of two fingers. Four months later his fingers had healed well, creatine phosphokinase activity was normal, and muscle power was satisfactory with prednisolone $10 \mathrm{mg}$ daily. Over the next year the fibrosing alveolitis progressed with right heart failure, responding temporarily to bumetanide $2 \mathrm{mg}$ daily. Muscle weakness recurred with a modest rise in creatine phosphokinase activity and multiple small ulcers appeared on his hands and ankles. He died of right-sided heart failure four years after clinical onset.

CASE 2

A 76-year-old woman with an eight-year history of Raynaud's and Sjögren's syndrome developed subacute small intestinal obstruction, which was managed conservatively. Weight loss of $19 \mathrm{~kg}$ over the preceding two years and oesophageal reflux had been noted at the time. Barium enema showed multiple wide-mouthed diverticula throughout the large bowel.

Two years later she developed severe scleroderma of the hands over five months, with rapidly progressive loss of hand function. Skin changes and telangiectasias of the face were noted. There was subluxation of the metacarpophalangeal joints and some ulnar deviation of the fingers. Schirmer's test was positive. Haemoglobin concentration was $11.4 \mathrm{~g} / \mathrm{dl}$ and erythrocyte sedimentation rate $24 \mathrm{~mm}$ in 1st hour; a latex test was positive but the results of sheep-cell agglutination and antinuclear factor tests were negative. Thyroid function tests and chest radiography were normal, and there was no calcinosis in $x$-ray films of the hands.

\section{Comment}

Although the highest reported incidence of scleroderma occurs in patients over $65,{ }^{1}$ it has been suggested that most patients in this age group have a benign form of the disease, ${ }^{23}$ often corresponding to the CRST syndrome (calcinosis, Raynaud's phenomenon, sclerodactyly and telangiectasis). Of 17 patients reported in two papers, ${ }^{3}$ all were women and only one had systemic disease (pulmonary fibrosis) apart from oesophageal lesions. No deaths attributable to the disease were reported.

Both our patients developed scleroderma after the age of 65 , with Raynaud's disease as an initial feature. Both had appreciable weight loss and severe progressive skin changes. The first patient was unusual in being a man and having the systemic complications of fibrosing alveolitis and polymyositis and a rapid progression of disease leading to death from right heart failure within four years of onset. The other patient had Sjögren's syndrome, oesophageal reflux, probable disease of the small and large bowel, and hand changes sufficient to cause considerable incapacity.

Scleroderma in the elderly, therefore, is not always benign. Our patients were not selected for the severity of the condition but were two consecutive patients aged over 65 , confirmed as having scleroderma after referral to a rheumatologist from general practice. The mild nature of the cases in the published series may be due to a Berkson-type bias. ${ }^{5}$

1 Rodnan GP. A review of recent observations and current theories on the etiology and pathogenesis of progressive systemic sclerosis. $\mathcal{f}$ Chronic Dis 1963;16:929-49.

2 Anonymous. Systemic sclerosis in old age. Br Med F 1979;ii:1313.

3 Hodkinson HM. Scleroderma in the elderly with special reference to the CRST syndrome. F Am Geriatr Soc 1971;19:224.

- Dalziel JA, Wilcock GK. Progressive systemic sclerosis in the elderly. Postgrad Med F 1979;55:192.

Mainland D. Berkson's fallacy in case-control studies. $\mathrm{Br}$ Med $\mathcal{F} 1980$ 280:330.

(Accepted 12 December 1980)

Northwick Park Hospital, Watford Road, Harrow, Middlesex HA1 3UJ

P L WILLIAMS, MB, MRCP, registra

J M GUMPEL, FRCP, consultant physician 